\title{
In Search of the Affective Subject Interacting in the ROODA Virtual Learning Environment
}

\author{
Magalí Teresinha Longhi, Patricia Alejandra Behar, and Magda Bercht \\ Programa de Pós-Graduação em Informática na Educação, Federal University of Rio Grande \\ do Sul (UFRGS), Caixa Postal 5071 - 90.041-970 - Porto Alegre - RS - Brazil \\ mlonghi@cesup.ufrgs.br, pbeharaterra.com.br, bercht@inf.ufrgs.br
}

\begin{abstract}
This paper examines elements from Piaget's and Scherer's theories that are able to offer subsidies for the specification of the affective aspects involved in Virtual Learning Environments (VLE). The affective dimension is characterized by the moods manifested during interactions in virtual space by affective portion of psychological subject. To figure moods out is a way to personalize the pedagogical activities and to understand the student's actions and competence.
\end{abstract}

Keywords: Affective subject, psychological subject, moods, virtual learning environment.

\section{Introduction}

Students learn through widely varying levels of competence, depending on the individual skills and structures formed but also the social environment exposure. The term competence can take on different meanings and here we use Le Bortef's definition. The author has defined competency as a result of a combination of several individual resources and of resources from the environment [1]. The individual resources are classified as the knowledge (theoretical, environmental and procedural), know-how (formalized, empirical, relational, and cognitive), skills or qualities, physiological and emotional resources.

The learning based of competence involves a variety of different dimensions. We are interested in how the affective dimension takes part in learning. The recognition of the student's affective dimension in Virtual Learning Environment (VLE) is an important resource for a teacher's practice in Distance Learning. We verify relationships between Piaget's [2] and Scherer's [3] theories regarding the definition of the affective subject and the emotional aspects involved in the VLE interactions.

VLE is understood as "space on the Internet, which is formed by subjects and their interactions and ways of communicating that are established by means of a platform" [4](p. 29). This platform is constituted by a technological infrastructure (graphic interface, synchronous and asynchronous communication tools and other functionalities) and by all the relationships (cognitive, affective, and symbolic) established by the subjects in this environment. 
In Piaget's theory, cognitive development is related to three interrelated types of factors that define the psychological subject: organic, mental, and social factors. Interactions are understood according to Piaget's presuppositions [5] that knowledge is constructed from the interactions between the psychological subject and the environment. For the author, mental factors are divided in cognitive, affective and symbolic factors, which are inseparable despite the fact they are different.

The psychological subject, according to Dolle [6,7], inspired by Piaget, is formed by: social, affective, cognitive, and biophysiological subjects. In order to explain the psychological subject in virtual space, Behar [8] presents a model of interaction between the subject and the computational environment. This suggests a resignification of the biophysiological dimension and proposes the VLE-subject. In a virtual environment, the subject acts by means of the hardware and the software and, therefore, the subject should know the technologies related to the interaction. Thus, after the evaluation of the VLE-subject, the technological subject becomes the new dimension of the psychological subject.

The affective subject is represented not only by the relationship with other subjects that form the VLE-subject, but also by all the organic components that participate in the evaluation and activation of an affective phenomenon. Scherer's theory [9] presupposes that the affective subject is formed by the organic components and the processes involved can explain the several affective phenomena experienced by the psychological subject. Scherer's theory offers subsidies in order to identify moods, which are factors associated with the way of cognitive processing and the reorganization of information in memory.

From this perspective, the studies undertaken by Dolle [6, 7] and Behar [8], regarding the affective and technological dimensions of the psychological subject, and by Scherer [3, 9], regarding the definition of the components that form the affective subject, are fundamental. Thus, this investigation intends to present the connections between the theoretical approach and the data collected in a VLE, in this case ROODA $^{1}$, with the purpose of evaluating the possibility of recognizing the affective dimension in such environment. In this study, the affective dimension is characterized based on the students' moods evidenced during interactions in virtual space.

In the next section, the interactions among psychological subjects in a virtual environment are mapped. In section 3, the Piaget's theory of affectivity is approached; whereas section 4 presents a report on the CPM model, which explains how an affective phenomenon is processed. In section 5 presents a mapping of the affective subject in the ROODA virtual environment and, in section 6, final considerations are made.

\section{Understanding the VLE Interactions of the Psychological Subject}

The virtual learning environment is a new setting of interaction for psychological subjects. Dolle [6] defines setting as a system formed by subjects, objects and rules (Figure 1). The subjects or people are the users of the environment (students, teachers,

${ }^{1}$ The ROODA (Cooperative Learning Net), available at http://rooda.edu.ufrgs.br, is one of the platforms made available by UFRGS for presences and distance lessons. 
tutors). Artificial objects refer to the resources made available in the environments, such as, contents, forums, chats, etc. The institutional rules regulate the interindividual relationships in the environment, as well as the way the tools made available are used.

Dolle's psychological subject (Figure 1) is constituted by the biophysiological subject, or everything that is related to the body, that is, all the biological and physiological functions (genetics, neurology, neurobiology, biochemistry, etc.); by the cognitive subject, that, when he acts, acquires knowledge of himself and of the setting; by the affective subject, whose activities are reflected in the form of emotions, feelings or effects of the relationships established; and, by the social subject, who is the interiorization of the habits, rules, and the social interdicts of any type. The elements that constitute the setting and the psychological subject lead to the interactionist scheme subject $\Leftrightarrow$ setting presented in Figure 1 .

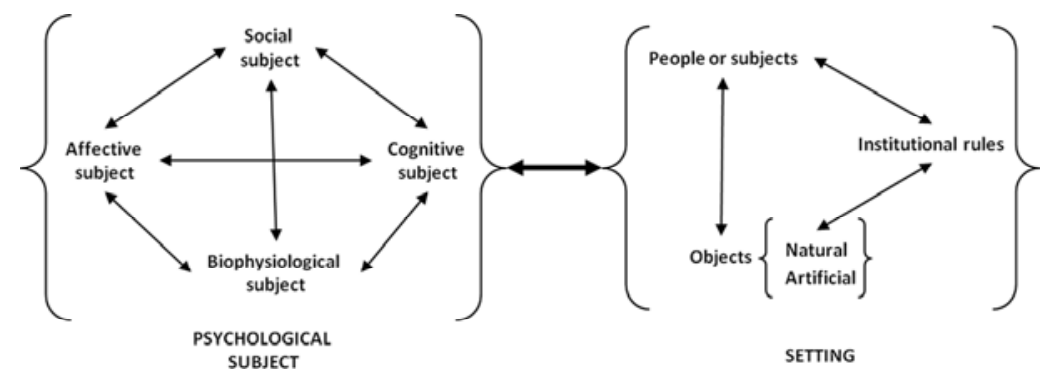

Fig. 1. Graphics of the relationship between the psychological subject and the setting [6]

Thus, the psychological subject relates to the setting VLE considering the presence of other psychological subjects, as well as the resources made available in the setting and the rules that, explicitly or not, lead or guide the relationships in this environment. Behar, based on the mental factors proposed by Piaget [5], presents a model to portray the process of interaction of a psychological subject with a computational tool [8]. This way, Behar defines the technological subject as the portion of the psychological subject that makes use of specific hardware and software to interact with the setting. According to what is illustrated in Figure 2, the psychological subject is redefined as a VLE-subject.

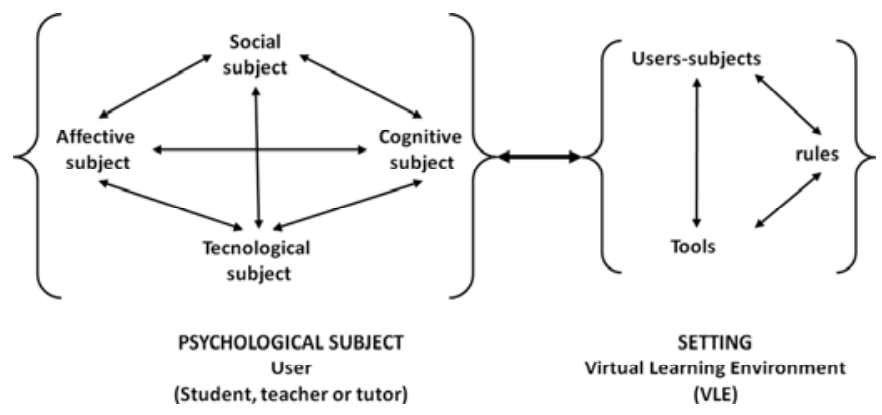

Fig. 2. Representation of the VLE-subject [10] 


\section{Piaget's Theory of Affectivity}

Piaget [11] dedicated to investigate the process of acquisition of knowledge, and how it develops. This way, Piaget highlighted, in the activity of the subject (S), both what originates from the subject and what originates from the object of knowledge $(\mathrm{O})$. That is, the relationship $\mathrm{S} \Leftrightarrow \mathrm{O}$, in which learning is "building".

Learning involves the action of $\mathrm{S}$ upon $\mathrm{O}$ and awareness of the coordination of these actions. In other words, S (for example, the student) will learn something new, or will build some new knowledge, if (1) $\mathrm{S}$ acts upon $\mathrm{O}$ (for example, study material) and (2) if $\mathrm{S}$ is able to assimilate $\mathrm{O}$ or appropriating of the "intimate mechanisms of their actions" [12] (p.23) upon O.

Piaget rejects the belief that $\mathrm{S}$ brings, in his or her genetics, ready cognitive structures (apriorism) for the acquisition of knowledge. He also rejects the idea that the social environment determines the structures of knowledge in S (empiricism). Piaget believes knowledge is built, and this happens in two complementary dimensions: as content-knowledge and as structure-knowledge (or form-knowledge) [12]. Contentknowledge refers to observable data, that is, "objects as such or actions of the subject upon his or her material characteristics" [13] (p. 274) and non-observable data, that is, the coordination of the actions, subjective observation (liking or not liking, being pleasurable or not, etc.); whereas structure-knowledge refers to the previous condition of knowledge, that is, how the structures are organized based on the activity of S.

Cognitive development happens at four stages: sensorimotor, preoperational, concrete operational and formal operational. In general terms, stage is a landmark of an evolution towards the balance of actions and mental operations. The duration of the subject at each stage depends on individual factors and on the setting [14]. And learning evolves from simple and concrete to complex and abstract schemes by means of two mechanisms: assimilation and accommodation. In the first, $\mathrm{S}$ acts, assimilating something (content-knowledge) from the environment (physical or social). In the second, the content assimilated, as it brings novelty, disturbs $S$ who needs to reconstruct his or her assimilation tools, incorporating the new content to the former scheme, reorganizing the scheme, accommodating. During accommodation, $\mathrm{S}$ modifies the assimilating scheme (structure-knowledge), and, thus, modifies him or herself.

Piaget presents the theory of the reflecting abstraction, at the level of symbolic exchange, mainly at the level of language and social relations, as "one of the motors of cognitive development and as one of the aspects of the more general processes of balance" [13] ( p. 274). Based on this, the author distinguishes empirical abstraction from reflecting abstraction (abstraction réfléchissante). The first one "is based on physical objects or on material aspects of actions, such as movements, pushes, etc." [13] (p. 5). Differently, the second one "is based on such forms and on all cognitive activities of the subject (schemes or coordination of actions, operations, structures, etc.), in order to withdraw some characteristics from them and use them with other purposes (new adaptations, new problems, etc.)"[13] (p. 6).

Reflecting abstraction, analyzed based on reflecting degrees, comprises two aspects: the first one, which Piaget calls réfléchissement is the one in which the subject, in several stages, elaborates a projection (as by a reflector) to the higher plane of what was brought from the lower plane; and the reflection (réflexion), or the mental act of 
reconstructing and reorganizing at the higher plane of what was transferred from the lower plane [13]. The formation of each plane can be represented by a spiral process, according to what is demonstrated in Figure $3^{2}$.

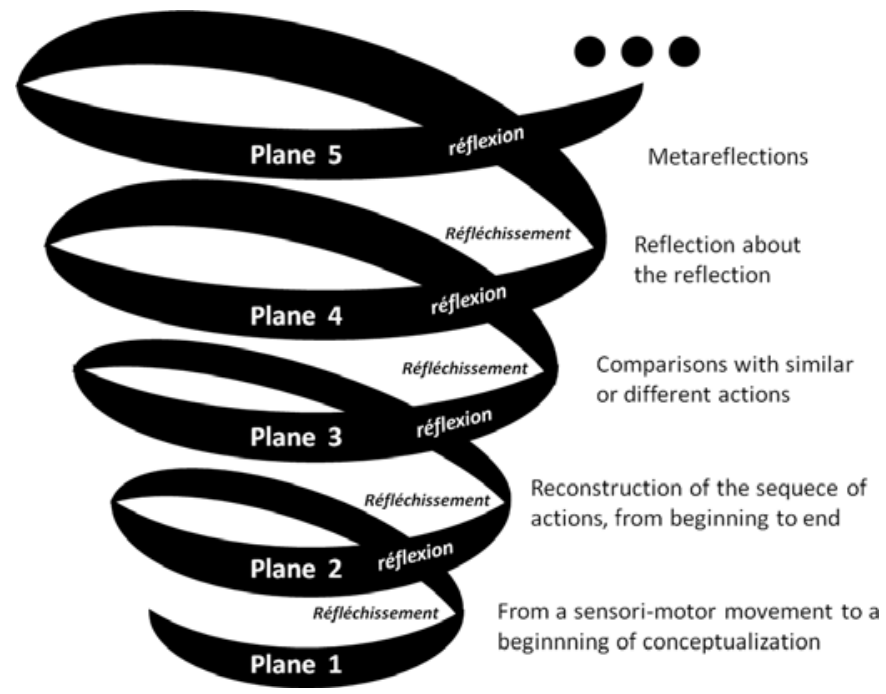

Fig. 3. Representation of the reflecting degrees

At the first plane, the most elemental réfléchissement leads to a sensorimotor movement to the first conceptualizations, that is, from reflexes and instinct to the first acquisitions such as habits, perceptions, and language. At the second plane, S already reconstructs a sequence of actions from beginning to end. The third plane is that of comparisons between analogue or different situations. At the fourth plane, $\mathrm{S}$ already makes "reflections" about the preceding reflections, continuing this process ad infinitum for the next planes reaching several degrees of metareflection or reflexive thought (réflexive).

Piaget warned that there is not a purely cognitive state or a purely affective state [2]. He recognized that affectivity is the motivating agent of cognitive activity, the source of energy of the structures or the motor of the action. Affectivity is not the structure, neither the action, and it does not change cognitive structures. Affectivity is characterized by positive or negative links between $\mathrm{S}$ and $\mathrm{O}$. The first ones explain the acceleration in intellectual development when $\mathrm{O}$ is interesting or necessary for $\mathrm{S}$. The second ones, however, explain the retardation when the affective situation related to $\mathrm{O}$ is an obstacle to $\mathrm{S}[2][15]$.

Dolle's hypothesis [7] is that the logic of affectivity is similar to that of cognitive processes, similar to that of cognitive stages. During the process of individual development, both logics operate synchronically, bur at a certain moment affectivity dominate

${ }^{2}$ The term réfléchissement has no equivalent in English. Therefore, in the figure, the terms used by Piaget himself are used to explain reflecting abstraction. 
and at another cognition dominate. This way, the subject restructures the foundations of his or her relationship with the world [7], as intelligence is reconstituted after affectivity itself is constituted (affectivity $\Leftrightarrow$ intelligence $\Leftrightarrow$ affectivity $\Leftrightarrow$ intelligence) [6]. Thus, the biophysiological subject leads to the affective subject, and this to the cognitive subject by integrations and achievements, which, in its turn, constitutes the social subject, following a spiral hierarchy, as presented in Figure 4.

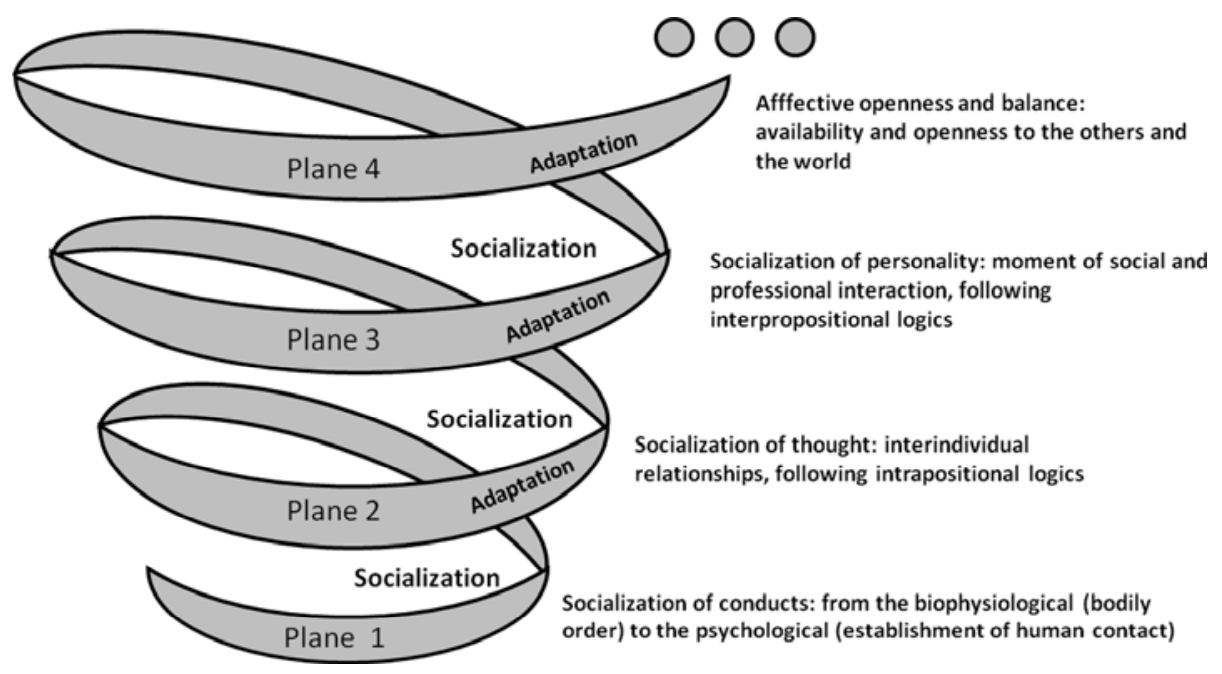

Fig. 4. Representation of the stages of the affective subject

As well as the terms réfléchissement-reflection, the socialization aspect refers to the plane above what is obtained from the plane below, and adaptation is the act of integrating or reorganizing affectivity. Thus, at the first plane, socialization of conducts leads to an instinctive tendency to perceptive affections (pleasure and pain, liking and disliking) and of elemental regulation (feeling of success or failure). At the second plane, the psychological subject possesses the symbolic function that enables a socialization of thoughts by means of interindividual relationships, facing the first elemental social and moral feelings. The third plane is that of normative affections, of the manifestation of autonomous moral feelings, of the socialization of personality. At the fourth plane, interindividual feelings grow with collective feelings. There is affective opening and balance that extend to the other planes.

In this study, the term cognition is understood not only as processing of information or mental functioning, but also as the capacity to react to what is perceived in the internal and external worlds. This also includes, besides the cognitive subject, the affective, the social and the biophysiological subjects. In epistemological terms, it is impossible to discuss réfléchissement and reflection without dealing with affective socialization and adaptation. Figure 5 illustrates the entwinement of the cognitive subject and the affective subject.

On the other hand, Scherer's theory [9][16] provides grounds in order to differentiate and understand how affective phenomena are processed in the organic subsystems. 
This way, the purpose is to identify the moods and also which of them are more related to learning.

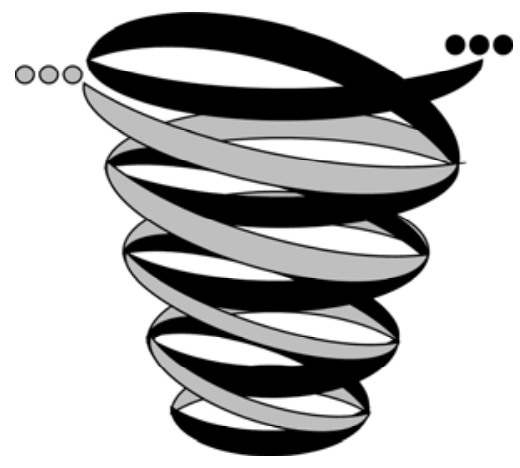

Fig. 5. Entwinement of the cognitive and the affective subjects

\section{Scherer's Theory of Affectivity}

The term affectivity usually refers to the ability to experience positive or negative feelings, and react to them. It is employed so as to identify psychic and physical phenomena associated with the terms emotion, mood, motivation, feeling, passion, love, personality, temperament, and many others refer to affectivity. Scherer [3] considers the terms related to affectivity to be affective phenomena. A phenomenon can be a state (disposition of the individual at a given moment) or a process (sequence of states or succession of changes that can transform the individual's disposition). However, the term emotion is commonly used to refer to the whole set of affective phenomena.

In order to define and distinguish affective phenomena, Scherer [3] established criteria to classify them as: 1) preferences (like, dislike), 2) attitudes (hate, esteem, desire), 3) moods (cheerful, glad, satisfied, willing, hopeless, upset, dissatisfied, suffering, indifferent, absent-minded, hopeful), 4) affective dispositions or personality traits (nervous, anxious, peevish, carefree, negligent, gloomy, melancholic, hostile, quarrelsome, cross, crabby, envious, jealous, curious, flexible, active, insecure, depressive, suspicious), 5) interpersonal postures or affective styles (polite, reserved, cold, warm, encouraging, disdainful, organized, sociable, kind), 6) utilitarian emotions (anger, fear, happiness, sadness, aversion, shame, guilt) and 7) aesthetic emotions (admiration, ecstasy, fascination, harmony, disagreement, solemnity, surprise, persuasion).

Leventhal \& Scherer proposed a multilayered structure to explain emotional processing [17]. The sensorimotor level comprises a set of innate brain programs and activation systems stimulated automatically, without any volitive effort, comprising internal and external changes of the subject. The schematic level is automatic, and integrates the processes evaluated no level below (sensorimotor) with images stored from emotional situations that have already happened (memory or emotional experience). The conceptual level activates memory to compare two or more emotional episodes. These three levels correspond to the stages of cognitive development proposed by Piaget. 
At each of these levels, processing comprises a sequential evaluation in four stages known as appraisal process ${ }^{3}$ : (1) the relevance of the event; (2) the hedonic valence or the implication of the event in the well-being and immediate achievement of the objectives; (3) the coping potential or the capacity of overcoming (or facing obstacles) that the subject is able to produce; and (4) the meaning of the event, based on the subject's social rules and values.

According to Scherer's model [16], also known as Component Process Model $(\mathrm{CPM})^{4}$, affective phenomena are explained after the evaluation of an event that triggers an emotional episode. The psychological subject constantly scans the external and internal environment to detect, evaluate, and reevaluate changes (appraisal process). In each stage of the appraisal process, which occurs in the Central Nervous System, information are projected to the other organismic subsystems to be processed or not such as support or autonomic physiology, executive or action tendencies, communication or motor expression and monitor or subjective feeling.

As soon as the psychological subject detects an event, the subject needs a minimal attention, reorganized according to the relevance of the event, as the first selective filter of the appraisal process. Then, if the event is important for the objectives of the psychological subject, such information is passed on to the other components, which can trigger or not the kind of physiological reaction, the action to be executed, the way of expression and indication of subjective feeling. This happens, successively, for each stage of the appraisal process. The CPM model proposes that changes in the internal and external events are analyzed up to the moment the monitor subsystem signals the termination or adjustment of the resulting feeling to the emotional episode evaluated [16][18].

Sherer's model is appropriate to define and explain several affective phenomena. Among them, moods, which can trigger, inhibit or even prevent learning. They can be thought as a summary of affective responses [19], which include the various components (cognitive, physiological, expressivity, motivational and subjective) of the evaluation that the subject makes.

Considering how moods influence memory and learning, Bower [20] formulated an important theory - Bower's theory. The author considered that an event would be represented in memory in cluster of propositions. These propositions would be recorded in memory when associations between the affective episode experienced and the cognitive concepts that participated in the event are made, suggesting that there would be a congruence of the mood. For Bower, the correspondence between the affective value of a piece of information and the subject's mood during its exposition influences if it will be apprehended in memory or not. Such hypothesis has great experimental support (see [19]).

Based on Piaget's concepts assimilation and accommodation and Piaget's view on the affectivity, it is possible to relate the moods to the cognitive performance. Positive moods support the processes of assimilation, leading to new beliefs or reelaborating existing ones in learning. In the accommodation process, they modify existing mental

\footnotetext{
${ }^{3}$ The concept of appraisal was introduced by Magda B. Arnold in 1960. Initially, the subject performs an instant evaluation of the situation. The emotion constitutes the product of this evaluation. When the emotion is expressed, it is accompanied by an underlying feeling. Thus, even though the process of evaluation is unconscious, its effects are conscious.

${ }^{4}$ Sander and colleagues [18] elucidate and illustrate the CPM processes.
} 
schemes more quickly. On the other hand, negative moods might make it harder to incorporate new data in the operative or action schemes or, even, encourage the learner to update beliefs in face of new knowledge. However, when related to the activation of the accommodation process, they might make things harder for the mechanisms of adaptation that structure and trigger cognitive development.

\section{Mapping of the Affective Subject in ROODA VLE}

In previous sections, the theoretical foundation presented offer subsidies for the analysis of the interactions in the ROODA VLE, with the aim of mapping the affective dimension starting from the cognitive and technological subjects. Piaget's theories and Scherer's theory are used to find evidence of the affective subject in the VLE-subject constructed by Behar [8] and Bassani [10]. Although in the VLE-subject Dolle's biophysiological dimension has suffered a resignification (technological subject), in this study it is applied again, as the importance of the organic components in the construction of the affective subject is verified, as presented in Scherer's theory. Thus, the VLE-subject may be represented as illustrated in Figure 6.

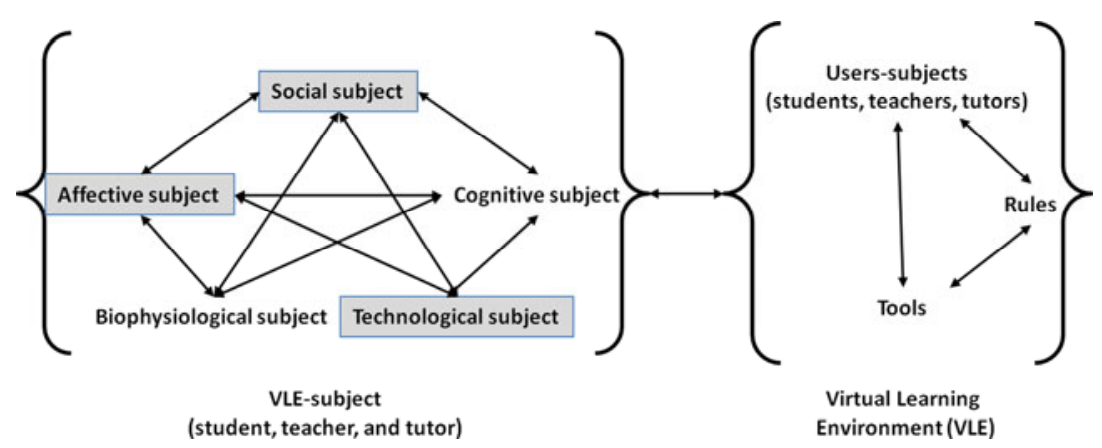

Fig. 6. Representation of the interaction VLE-subject and the study subjects

The affective dimension, which is emphasized in this study, is characterized by the externalization or not of the affective phenomena triggered during the processes that follow the other dimensions. Thus, it was decided that the moods would be approached because they are among the most representative affective phenomena in the scope of learning. With this purpose, the mood markers being cheerful, cheerless, satisfied and dissatisfied [21].

The social dimension comprises the construction of a learning virtual community by means of individual or interindividual relationships. It is characterized by the interiorization of the rules by the virtual environment, and by the interactions established with other user-subjects. The quality of the interactions may be analyzed based on the symmetry between the number of accesses and the quality of the relationships formed (social exchanges) [10].

The technological dimension determines to what point the VLE-subject is open to new technologies. It makes reference to the technological knowledge that the 
VLE-subject should have to communicate and feel as participating in the virtual environment. But, it also recognizes the limitations of the VLE-subject in face of the environment. In this study, difficulties with the operationalization of the environment, technical problems and the technological knowledge necessary for the use of the environment are considered.

The biophysiological dimension of the VLE-subject can be defined based on studies about the observable behavior of the body, such as body gestures, facial expressions, muscular tension, skin conductivity, breathing, cardiac rhythm, temperature and eye movements etc., by means of visual (cameras), audio (microphones) and/or physiological sensors (seats sensitive to the pressure of the body, gloves that capture the skin conductivity, mouse sensitive to the "quality" of the pressure, EEG, ECG, ERP, thermographs, devices to measure pulsation, breathing and pupil dilation are examples of tools used to measure physiological data).

The cognitive dimension, in its turn, makes references to the processes of construction of knowledge of the object of study (content, subject, learning object, etc.), which are thoroughly discussed by Piaget and many other authors.

Figure 7, using the semantic network proposed by Bower [20], illustrates some of the studies conducted by the authors in order to evaluate the connections among the various subjects that make up the VLE-subject.

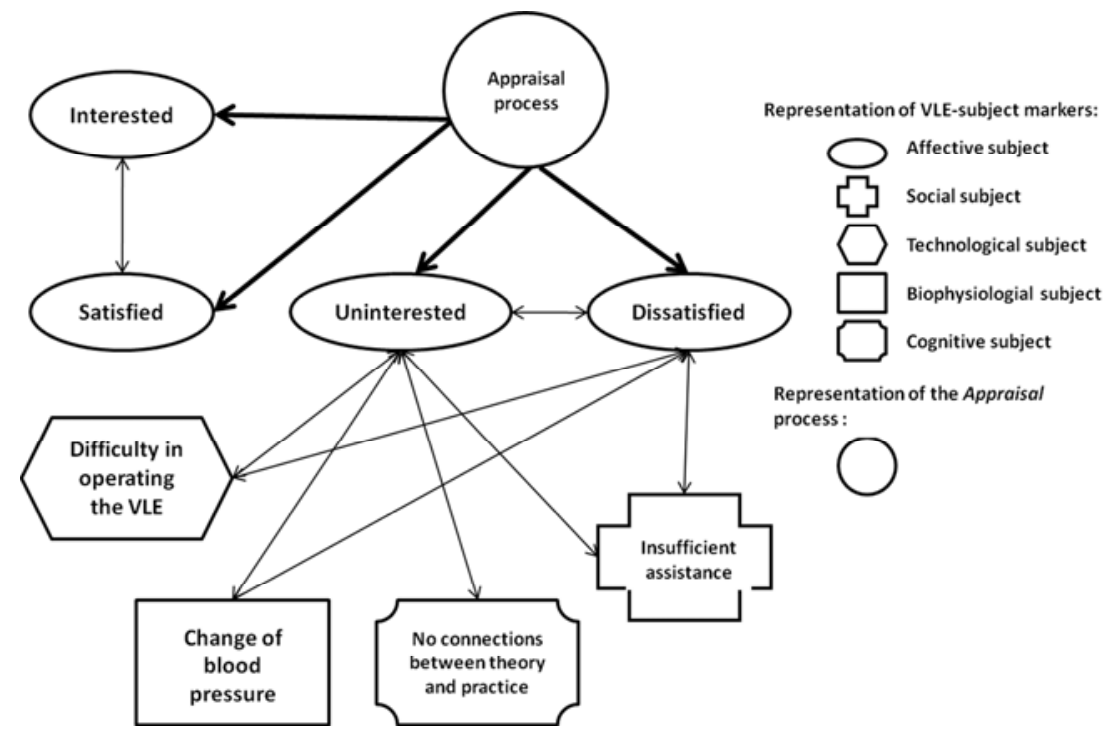

Fig. 7. Markers of the VLE-subject

The biophysiological and the cognitive dimensions will not be dealt with in this research as they are being studied by researchers at the Graduate Program in Computer Science Applied to Education at UFRGS. Studies that deal with the biophysiological dimension have just started to be conducted and several other studies focus on the cognitive dimension. 


\section{Final Considerations}

In face of the various studies on the role of the affective dimension in human learning, affective phenomena contribute to the internal representation of the object of knowledge, and affect the way the individual learn, takes decisions, and behaves in social interactions. Affective dimensions influence the learning both positively and negatively. In the first, the sense of challenge, persistence, enthusiasm, curiosity, the satisfaction of completing a task, favor the student in consolidating the knowledge acquired, motivating the student to continue acquiring new knowledge. In the second, there is fear, uncertainty, resignation, anxiety, indifference, lack of confidence, boredom, etc. and might discourage the student to take a course or even lead him to quit a course. The affective state experienced during an activity is, mostly, determined by the characteristics and content of the task, as well as the pedagogic strategy applied.

Maehr [23], when referring that school motivation is related to the affective states of the student, suggests that the studies should be redirected: "If they energize [the learning], how do they do so? If they undermine or confound, why and when? Again, the focus on self and self-worth reinforces the need to rediscover the role of the emotions in motivation" (p. 184).

It can be noticed that digital technologies, mainly in a virtual context, promote changes of the relationships among learning agents: teachers, students, and tutors. In their turn, the analyses and studies that are necessary to accommodate these new paradigms need theories that validate them. With this purpose, this article emphasizes Scherer's and Piaget's contributions with the purpose of analysis and interpretation of the affective subject in interaction in VLE (VLE-Subject).

In fact, it is noticed that Piaget does not conceive of a process of réfléchissement and reflection without having as a premise the inherent affectivity, the subject's values. Scherer, in his turn, defines moods as processes and a way of analyzing how such processes are processed in a subject.

Therefore, this study defends the importance of the inference of the moods in virtual learning environments and, for this reason, is being developed, in the scope of the ROODA VLE, an instrument capable of providing this. It is expected that these environments soon transform from mere content repositories or means of communication to also instruments that might assist us to re(think) possible modifications in Distance Learning actions.

Acknowledgments. This study is been supported by the Brazilian agency CNPq (National Council for Scientific and Technological Development). The authors would like to thank Prof. Fernando Becker for ideas, suggestions and critical comments about the text.

\section{References}

1. Le Boterf, G.: Desenvolvendo a competência dos profissionais (Translated by Reuillard, P.C.R.), Porto Alegre, Artmed (2003)

2. Piaget, J. Inteligencia y afectividad. Aique, Buenos Aires (2005) 
3. Scherer, K.: What are emotions? And how can they be measured? Social Science Information 44(4), 695-729 (2005)

4. Behar, P.A.: Modelos Pedagógicos em Educação a Distância. Artmed, Porto Alegre (2009)

5. Piaget, J.: Estudos sociológicos. Forense, Rio de Janeiro (1973)

6. Dolle, J.M.: Para além de Freud a Piaget: referenciais para novas perspectivas em psicologia. Vozes, Petrópolis (1993)

7. Dolle, J.M.: De Freud a Piaget: Elementos para um enfoque integrador de La afectividad y la inteligência. Paidos, Buenos Aires (1979)

8. Behar, P.A.: A lógica operatória e os ambientes computacionais. In: Anais do SBIE 1999 X Simpósio Brasileiro de Informática na Educação, Curitiba, PR (November 1999)

9. Scherer, K.R.: Appraisal considered as a process of multilevel sequential checking. In: Scherer, K.R., Schorr, A., Johnstone, T. (eds.) Appraisal Processes in Emotion: Theory Methods, Research, pp. 92-129. Oxford University Press, Oxford (2001)

10. Bassani, P.B.S.: Mapeamento das interações em ambiente virtual de aprendizagem: uma possibilidade para avaliação em educação a distância. PPGIE/UFRGS, Porto Alegre (2006)

11. Piaget, J.: A epistemologia genética (Translated by Caixeiro, N.C.). Abril Cultural, São Paulo (1978)

12. Becker, F.: Educação e Construção do Conhecimento. Artmed, Porto Alegre (2001)

13. Piaget, J.: Abstração reflexionante: relações lógico-aritméticas e ordem das relações espaciais (Translated by Becker, F. \& Silva, P.B.G.). Artes Médicas, Porto Alegre (1995)

14. Montangero, J., Maurice-Naville, D.: Piaget: ou a inteligência em evolução (Translated by Marques, T.B.I. \& Becker, F.). Artmed, Porto Alegre (1998)

15. Piaget, J.: Problemas de Psicologia Genética. Forense, Rio de Janeiro (1973)

16. Scherer, K.R.: Toward a dynamic theory of emotion: The component process model of affective states. Geneva Studies in Emotion and Communication 1, 1-98 (1987)

17. Leventhal, H., Scherer, K.R.: The relationship of emotion and cognition: A functional approach to a semantic controversy. Cognition and Emotion 1, 3.28 (1987)

18. Sander, D., Grandjean, D., Scherer, K.R.: A systems approach to appraisal mechanisms in emotion. Neural Networks 18, 317-352 (2005)

19. Mayer, J.D., Hanson, E.: Mood-congruent judgment over time. Personality and Social Psychology Bulletin 21, 237-244 (1995)

20. Bower, G.H.: Mood and memory. American Psychologist 36, 129-148 (1981)

21. Longhi, M.T., Behar, P.A., Bercht, M.: AnimA-K: recognizing student's mood during the learning process. In: WCCE 2009 - 9th IFIP World Conference on Computers in Education, Bento Gonçalves, RS, Brazil, July 27-31 (2009)

22. Pozo, J.I.: Aquisição do Conhecimento: quando a carne se faz verbo (Translated by Antonio Feltrin). Artmed, Porto Alegre (2004)

23. Maehr, M.L.: Goal theory is not dead-not yet, anyway: A reflection on the special issue. Educational Psychology Review 13(2), 177-185 (2001) 